\title{
SISTEM PENDUKUNG KEPUTUSAN UNTUK SELEKSI DOSEN MENGGUNAKAN METODE TOPSIS (STUDI KASUS : STMIK STIKOM BALI)
}

\author{
A.A Gde A Putra Ratu Asmara \\ Program Studi Sistem Informasi \\ STMIK STIKOM, Bali. \\ ratuasmara123@gmail.com
}

\begin{abstract}
STMIK STIKOM Bali is the first IT School (Information Technology) in Bali. STMIK STIKOM Bali was established in 2002, and until now STIKOM Bali has 189 permanent lecturers which are divided into 3 study programs, namely Computer System Study Program which has 69 Permanent Lecturers, Information System Study Program with 110 Lecturers and Management Studies Program Informatics has 10 Fixed Lecturers. In the duty as seoarang Lecturers should be able to do Tri Dharma Higher Education such as Research, Community Service, and Teaching. As a well-developed university and has quite a lot of lecturers, STIKOM Bali is obliged to give awards to the exemplary lecturers, the goal is to encourage other lecturers to perform and provide the best for Higher Education, Students, and for himself. For the researcher try to make a system to conduct the process of selecting the lecturer to give recommendation of lecturer names who will follow this selection. By conducting this selection process will facilitate the STIKOM Bali to get the results of the lecturer's model recommendation. Implementation of TOPSIS Method (Technique For Order Reference By Similarity To Ideal Solution) can be applied to provide alternative recommendations through calculations with different criteria.
\end{abstract}

Keywords : TOPSIS Methods, Decision Support Systems, STIKOM Bali

\begin{abstract}
ABSTRAK
STMIK STIKOM Bali merupakan Sekolah IT (Information Technology) yang pertama di Bali. STMIK STIKOM Bali berdiri pada Tahun 2002, dan sampai saat ini STIKOM Bali telah memiliki 189 Dosen tetap yang dibagi dalam 3 Program Studi, yakni Program Studi Sistem Komputer yang memiliki 69 Dosen Tetap, Program Studi Sistem Informasi dengan 110 Dosen Tetap, dan Program Studi Manajemen Informatika memiliki 10 Dosen Tetap. Dalam kewajiban sebagai seoarang Dosen harus dapat melakukan Tri Dharma Perguruan Tinggi seperti Penelitian, Pengabdian Masyarakat, dan Pengajaran. Sebagai Perguruan Tinggi yang sudah berkembang dengan baik dan memiliki cukup banyak dosen, STIKOM Bali berkewajiban untuk memberikan penghargaan kepada para dosen teladan, tujuannya adalah untuk memacu dosen lainnya agar dapat melakukan dan memberikan yang terbaik untuk Perguruan Tinggi, Mahasiswa, dan bagi dirinya sendiri. Untuk peneliti mencoba membuat suatu sistem untuk melakukan proses penyeleksian dosen teladan untuk memberikan rekomendasi nama-nama dosen yg nantinya akan mengikuti penyeleksian ini. Dengan melakukan proses penyeleksian ini akan memudahkan pihak STIKOM Bali untuk mendapatkan hasil rekomendasi dosen teladan. Implementasi Metode TOPSIS (Technique For Order Reference By Similarity To Ideal Solution) dapat diterapkan untuk memberikan rekomendasi alternatif melalui perhitungan dengan kriteria yang berbeda.
\end{abstract}

Kata Kunci: Metode TOPSIS, Sistem Pendukung Keputusan, STIKOM Bali. 


\section{PENDAHULUAN}

Perguruan Tinggi berkewajiban menyelenggarakan pendidikan, penelitian, dam pengabdian kepada masyarakat ketiga unsur tersebut disebut dengan Tri Dharma Perguruan Tinggi. Salah satu unsur dalam pelaksanaan tersebut adalah Dosen. Dosen merupakan tenaga akademik yang bertugas merencanakan dan melaksanakan proses pembelajaran, menilai hasil pembelajaran, melakukan pembimbingan dan pelatihan, serta melakukan penelitian dan pengabdian masyarkat. Berdasarkan Undang - undang Republik Indonesia No.14 tahun 2005 tentang Guru dan Dosen, Pasal 51 ayat (1) butir b, bahwa dosen berhak mendapatkan promosi dan penghargaan sesuai dengan kinerja akademiknya.

STMIK STIKOM Bali merupakan salah satu sekolah atau perguruan tinggi IT (Information Technology) di Bali yang berdiri sejak tahun 2002. STMIK STIKOM Bali memiliki 3 Jurusan, yaitu Sistem Komputer, Sistem Informasi, dan Manajemen Informatika. Saat ini STMIK STIKOM Bali memiliki jumlah Dosen Tetap sebanyak 189 dengan rincian Sistem Informasi sebanyak 110 Dosen Tetap, Sistem Komputer sebanyak 69 Dosen Tetap, dan Manajemen Informatika sebanyak 10 Dosen Tetap.

Dosen mempunyai kedudukan sebagai tenaga pendidik professional pada jenjang pendidikan di sebuah Perguruan Tinggi ataupun Sekolah Tinggi yang diangkat sesuai dengan peraturan peundang-undangan. Sehubungan dosen teladan tersebut maka pada STMIK STIKOM Bali dosen yang ada sekarang diharapkan mampu memberikan contoh yang baik untuk setiap mahasiswanya. Dengan adanya seleksi dosen teladan diharapkan apa yang menjadi tujuan dari Perguruan tinggi dapat terwujud. Hanya saja dalam Implementasi dilapangan terdapat beberapa kendala yang muncul seperti lamanya waktu yang dibutuhkan, setelah menyaring beberapa dosen langkah selanjutnya adalah memilih dosen teladan yang pantas untuk menerima penghargaan tersebut. Dengan permasalah tersbut maka peneliti mengembangkan perangkat lunak yang dapat membantu dalam seleksi pemilihan dosen teladan pada STMIK STIKOM Bali, hal ini diperlukan untuk membantu menyeleksi dosen teladan secara lebih tersistem sesuai dengan parameter yang digunakan dan meminimalisasi terjadinya kesalahan data. Dalam pengembangan aplikasi ini akan menerapkan metode TOPSIS. Metode TOPSIS (Technique For Order Preference by Similarity to Ideal Solution) merupakan salah satu metode pengambilan keputusan multikriteria atau merupakan alternative yang mempunyai jarak terkecil dari solusi ideal positif dan jarak terbesar dari solusi ideal negative dari sudut pandang geometris dengan menggunakan jarak Euclidean.

Penelitian ini membahas mengenai pengkajian, analisis dan pengembangan sebuah sistem penunjang keputusan menggunakan pencocokan profil yang bersifat mandiri yang bisa membantu institusi atau lembaga untuk memberikan reward sebagai penghargaan atas prestasi dari dosen pada institusi atau lembaga bersangkutan.

\section{METODELOGI PENELITIAN}

\section{Jenis dan Sumber Data}

Berdasarkan sumbernya, data dibedakan menjadi dua, yaitu data primer dan data sekunder.

Data primer adalah data yang diperoleh dari responden secara langsung yang dikumpulkan melalui survey di lapangan dengan menggunakan alat pengumpulan data tertentu yang dibuat secara khusus. Sumber data primer dalam penelitian ini, yaitu peneliti yang terlibat langsung dengan objek penelitian.

Data sekunder adalah data yang telah dikumpulkan oleh pihak lain atau lembaga pengumpul data dan dipublikasikan kepada masyarakat pengguna data. Sumber data sekunder dalam penelitian ini, yaitu pelaku yang tidak langsung berhubungan dengan objek penelitian, tetapi bersifat membantu dan memberikan informasi bagi penelitian. Data sekunder dari pihak lain yang berasal dari buku-buku, majalah, literatur, artikel, internet dan tulisan-tulisan ilmiah.

\section{Metode Pengumpulan Data}

Guna memperoleh data yang diperlukan dalam penyusunan laporan ini, penulis menggunakan metode pengumpulan data sebagai berikut.

Survey (Observasi atau Pengamatan Langsung) adalah suatu metode pengumpulan 
data dengan cara melakukan pengamatan langsung terhadap objek penelitian yang dalam hal ini adalah Dosen yang berada pada STMIK STIKOM Bali kulit tentang hal-hal yang dibutuhkan atau diperlukan, tidak terkecuali hardware dan software yang mendukung sistem.

Studi Pustaka adalah teknik pengumpulan data dengan cara mendapatkan informasi dari buku, laporan, internet yang berhubungan dengan obyek penelitian yang dapat digunakan sebagai landasan teori serta dapat dijadikan sebagai bahan perbandingan atau pelengkap.

\section{Pemodelan Perangkat Lunak}

Secara garis besar tahapan dalam penelitian Implementasi Metode TOPSIS untuk Seleksi Dosen Teladan (Studi Kasus : STMIK STIKOM Bali) ini terdiri dari:

Analisis sistem

Menganalisis Implementasi Metode TOPSIS untuk Seleksi Dosen (Studi Kasus : STMIK STIKOM Bali). Dalam tahap ini dibagi menjadi tiga langkah utama yaitu:

Mengidentifikasi masalah dan kebutuhan. Mengkaji situasi dan memutuskan dengan pasti tentang masalah yang akan dikomputerisasi dan apakah dengan Sistem Pendukung Keputusan bisa lebih membantu atau tidak.

Menentukan masalah yang cocok. Ada beberapa syarat yang harus dipenuhi agar sistem pakar dapat bekerja dengan baik, yaitu:

- Domain masalah tidak terlalu besar.

- Kompleksitas menengah, artinya jika masalah terlalu mudah (dapat diselesaikan dalam beberapa detik saja) atau masalah yang sangat kompleks.

- Menghasilkan solusi mental bukan fisik, artinya sistem pendukung keputusan hanya memberikan masukan atau pendukung dalam pengambilan keputusan.

Pecarian data-data dari berbagai sumber, baik data primer maupun data sekunder.

Rekayasa Pengetahuan

\section{Sistem Flow}

Sistem Flow merupakan bagan yang mengambarkan hubungan antara input, process dan output yang nantinya sistem tersebut dapat diimplementasikan ke sistem komputer. Bagan ini menjelaskan urutan prosedur-prosedur yang ada didalam sistem biasanya dalam membuat sistem flow ditentukan fungsi-fungsi yang dilaksanakan atau bertanggung jawab terhadap sub-sub sistem tersebut.

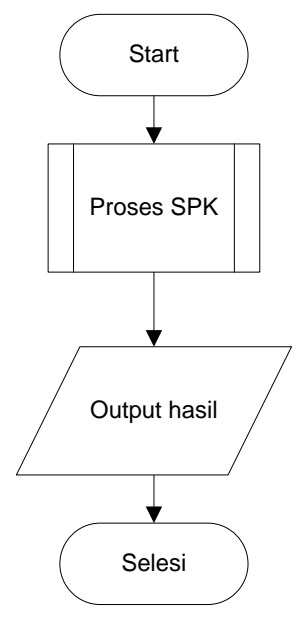

\section{Gambar 1. Sistem Flowchart}

\section{Diagram Konteks}

Entitas yang pertama yaitu admin, admin dapat melakukan manipulasi data seperti menambah, mencari, mengedit, menghapus terhadap keseluruhan data-data master yang ada dalam sistem ini, termasuk juga didalamnya admin dapat melakukan proses SPK untuk nantinya dapat diperoleh informasi rekomendasi guru teladan. Entitas yang ke dua yaitu Ketua STMIK STIKOM Bali, Ketua yang dalam hal ini adalah orang yang harus mengetahui dan menyetujui hasil dari proses seleksi dosen teladan dalam bentuk info report.

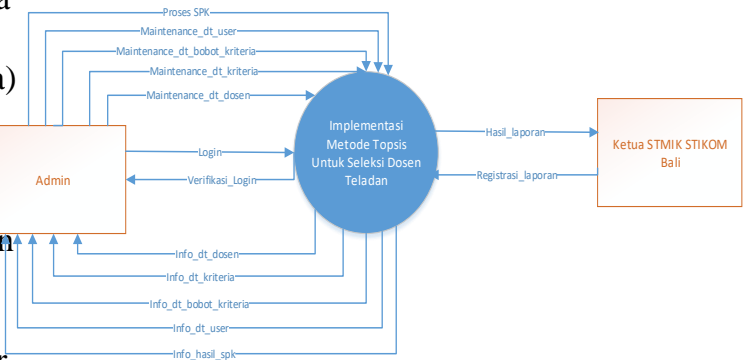

Gambar 2. Diagram Konteks

\section{Level 0}

Untuk mengetahui proses yang ada pada diagram konteks diatas, maka proses tersebut dipecah menjadi beberapa proses dimana proses tersebut merupakan proses yang terakhir dari alur data pada sistem yang telah dibuat. Dalam proses DFD level 0 mempunyai 7 proses yaitu proses login, maintenance user, maintenance kriteria, maintenance bobot kriteria, maintenance dosen, proses spk, laporan. Dan terdapat 3 
tabel yaitu tabel user, tabel kriteria, tabel bobot kriteria. Setiap proses sudah mempunyai data flow masing-masing.

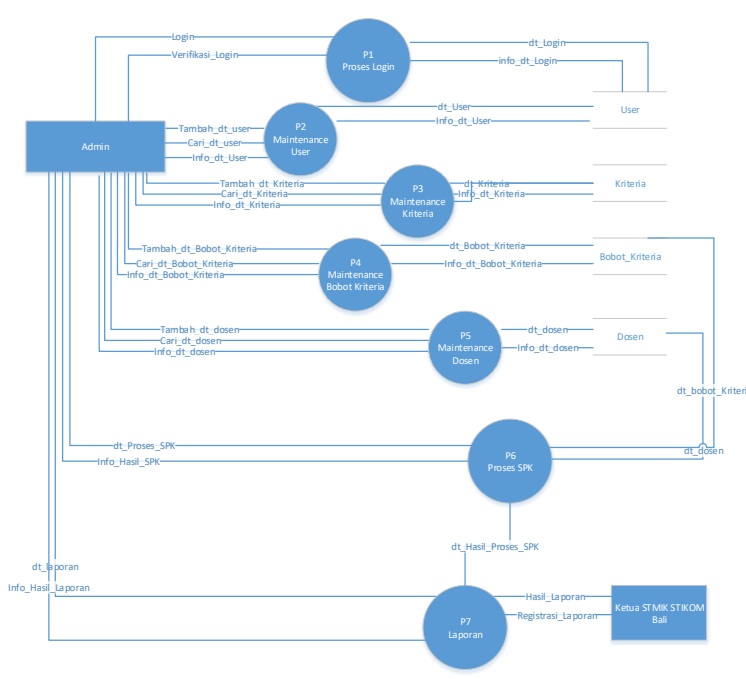

Gambar 3. Diagram Level 0

ERD

Entity Relationship Diagram (ERD) merupakan bagian yang menggambarkan hubungan atau relasi antar dua entity atau lebih. Entity merupakan objek di dunia nyata yang dapat dibedakan dari objek lain. Entity dan relasi dideskripsikan lebih jauh melalui sejumlah atribut. Setiap entity memiliki atribut yang mendeskripsikan karakteristik dari entity tersebut. Adapun rancangan entity relationship diagram sistem seleksi dosen teladan dengan menggunakan metode TOPSIS adalah sebagai berikut

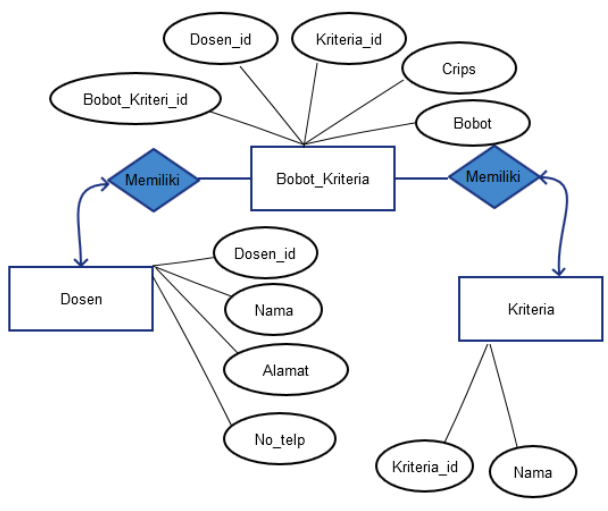

Gambar 4. ERD

\section{HASIL DAN PEMBAHASAN}

Kriteria yang dibutuhkan

Berikut merupakan kriteria yang dibutuhkan untuk Perancangan Sistem Seleksi Dosen Teladan Dengan Metode TOPSIS Pada STMIK STIKOM Bali.. Adapun kriteria yang telah ditentukan yaitu masa kerja $(\mathrm{C} 1)$, usia (C2), Penelitian (C3), Pengabdian Masyarakat (C4), Beban Mengajar (C5). Dari kriteria tersebut maka dibuat suatu tingkat kepentingan kriteria berdasarkan nilai bobot yang telah ditentukan. Rating kecocokan setiap alternative pada setiap kriteria sebagai berikut :

Keterangan :

- $\mathrm{C} 1=$ Masa Kerja

- $\mathrm{C} 2=\mathrm{Usia}$

- $\mathrm{C} 3=$ Penelitian

- $\quad \mathrm{C} 4=$ Pengabdian Masyarakat

- $\mathrm{C} 5$ = Beban Mengajar

Berikut nilai bobot untuk masing-masing kriteria :

1. Masa Kerja (C1)

\begin{tabular}{|l|c|}
\hline \multicolumn{1}{|c|}{ Crips } & Nilai Bobot \\
\hline$\geq 1.00, \leq$ & 1 \\
$4.00, \leq$ & 2 \\
\hline$\geq 4.00, \leq 0$ \\
$7.00, \leq$ \\
\hline$\geq 7.00, \leq$ \\
\hline $12.00,12.00, \leq$ \\
\hline 15.00 & 4 \\
\hline$>15.00$ & \\
\hline
\end{tabular}

2. Usia (C2)

\begin{tabular}{|l|c|}
\hline \multicolumn{1}{|c|}{ Crips } & Nilai Bobot \\
\hline$\geq 20, \leq 25$ & 1 \\
\hline$\geq 25, \leq 30$ & 2 \\
\hline$\geq 30, \leq 35$ & 3 \\
\hline$\geq 35, \leq 40$ & 4 \\
\hline$>40$ & 5 \\
\hline
\end{tabular}


3. Penelitian $(\mathrm{C} 3)$

\begin{tabular}{|l|c|}
\hline \multicolumn{1}{|c|}{ Crips } & Nilai Bobot \\
\hline$\geq 1.00, \leq$ & 1 \\
3.00 & \\
\hline$\geq 3.00, \leq$ & 2 \\
5.00 & \\
\hline$\geq 5.00, \leq$ & 3 \\
8.00 & \\
\hline$\geq 8.00, \leq$ & 4 \\
12.00 & \\
\hline$>12.00$ & 5 \\
\hline
\end{tabular}

4. Pengabdian Masyarakat (C4)

\begin{tabular}{|l|c|}
\hline \multicolumn{1}{|c|}{ Crips } & Nilai Bobot \\
\hline$\geq 1.00, \leq$ & 1 \\
3.00 & \\
\hline$\geq 3.00, \leq$ & 2 \\
5.00 & \\
\hline$\geq 5.00, \leq$ & 3 \\
8.00 & \\
\hline$\geq 8.00, \leq$ & 4 \\
12.00 & \\
\hline$>12.00$ & 5 \\
\hline
\end{tabular}

5. Beban Mengajar (C5)

\begin{tabular}{|l|c|}
\multicolumn{1}{|c|}{ Crips } & Nilai Bobot \\
\hline$\geq 1, \leq 3$ & 1 \\
\hline$\geq 3, \leq 5$ & 2 \\
\hline$\geq 5, \leq 7$ & 3 \\
\hline$\geq 7.00, \leq 9$ & 4 \\
\hline$>9$ & 5 \\
\hline
\end{tabular}

1. Mencari Tabel Kecocokan

\begin{tabular}{|c|c|c|c|c|c|}
\hline \multirow{2}{*}{$\begin{array}{c}\text { Alterna } \\
\text { tif }\end{array}$} & \multicolumn{5}{|c|}{ Kriteria } \\
\cline { 2 - 6 } & $\mathrm{C} 1$ & $\mathrm{C} 2$ & $\mathrm{C} 3$ & $\mathrm{C} 4$ & $\mathrm{C} 5$ \\
\hline $\mathrm{A} 1$ & 4 & 4 & 5 & 3 & 3 \\
\hline A2 & 3 & 3 & 4 & 2 & 3 \\
\hline A3 & 5 & 4 & 2 & 2 & 2 \\
\hline
\end{tabular}

Contoh :

Misalkan bobot yang akan di inputkan oleh user adalah :

$$
\mathrm{W}=(5,3,4,4,2)
$$

Pada setiap nilai yang diberikan di setiap alternatif kriteria merupakan nilai kecocokan (nilai terbesar adalah terbaik), maka semua kriteria yang diberikan diasumsikan sebagai kriteria keuntungan.

2. Normalisasi Matriks Keputusan

$$
r_{i j}=\frac{X_{i j}}{\sqrt{\sum_{i=1}^{m} X_{i, j}^{2}}}
$$

A. $\mathrm{C} 1$

$r_{1.1}=$

$\frac{4}{\sqrt{4^{2}+3^{2}+5^{2}}}=\frac{4}{\sqrt{16+9+25}}=\frac{4}{\sqrt{50}}=\frac{4}{7,0711}=$ 0,5657

$r_{2.1}=$

$\frac{3}{\sqrt{4^{2}+3^{2}+5^{2}}}=\frac{3}{\sqrt{16+9+25}}=\frac{3}{\sqrt{50}}=\frac{3}{7,0711}=$ 0,4243

$r_{3.1}=$

$\frac{5}{\sqrt{4^{2}+3^{2}+5^{2}}}=\frac{5}{\sqrt{16+9+25}}=\frac{5}{\sqrt{50}}=\frac{5}{7,0711}=$ 0,7071

B. $\mathrm{C} 2$

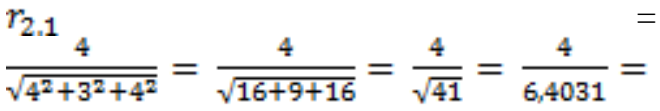
0,6247

$\frac{r_{2,2}=}{\sqrt{4^{2}+3^{2}+4^{2}}}=\frac{3}{\sqrt{16+9+16}}=\frac{3}{\sqrt{41}}=\frac{3}{6,4031}=$ 0,4685 
$r_{2 . a}$

$=\frac{4}{\sqrt{4^{2}+a^{2}+4^{2}}}=\frac{4}{\sqrt{16+9+16}}=\frac{4}{\sqrt{41}}=\frac{4}{64031}=$ 0,6247

C. $\mathrm{C} 3$

$r_{\mathrm{a} .1}$

$=$

$\frac{5}{\sqrt{5^{2}+4^{2}+2^{2}}}=\frac{5}{\sqrt{25+16+4}}=\frac{5}{\sqrt{45}}=\frac{5}{6,7082}=$ 0,7454

$r_{\mathrm{a} .2}$

$\frac{4}{\sqrt{5^{2}+4^{2}+2^{2}}}=\frac{4}{\sqrt{25+16+4}}=\frac{4}{\sqrt{45}}=\frac{4}{6,7082}=$ 0,5963

$\frac{2}{\sqrt{5^{2}+4^{2}+2^{2}}}=\frac{2}{\sqrt{25+16+4}}=\frac{2}{\sqrt{45}}=\frac{2}{6,7092}=$ 0,2981

D. $\mathrm{C} 4$

$r_{4.1}$

$\frac{a}{\sqrt{a^{2}+2^{2}+2^{2}}}=\frac{a}{\sqrt{9+4+4}}=\frac{a}{\sqrt{17}}=\frac{a}{4 \cdot 1231}=$ 0,7276

$r_{4.2}$

$\frac{2}{\sqrt{a^{2}+2^{2}+2^{2}}}=\frac{2}{\sqrt{9+4+4}}=\frac{2}{\sqrt{17}}=\frac{2}{4.1231}=$ 0,4851

$\frac{r_{4,3}}{\sqrt{3^{2}+2^{2}+2^{2}}}=\frac{2}{\sqrt{9+4+4}}=\frac{2}{\sqrt{17}}=\frac{2}{4,1231}=$ 0,485

E. C5

$r_{5.1}$

$\frac{a}{\sqrt{a^{2}+a^{2}+2^{2}}}=\frac{a}{\sqrt{9+9+4}}=\frac{a}{\sqrt{22}}=\frac{a}{4,6904}=$ 0,6396

$r_{5.2}=$

$\frac{a}{\sqrt{a^{2}+a^{2}+2^{2}}}=\frac{a}{\sqrt{9+9+4}}=\frac{a}{\sqrt{22}}=\frac{a}{4,6904}=$ 0,6396 $r_{5.9}=$

$\frac{2}{\sqrt{a^{2}+a^{2}+2^{2}}}=\frac{2}{\sqrt{9+9+4}}=\frac{2}{\sqrt{22}}=\frac{2}{4,6904}=$ 0,4264

Setelah Matriks ternormalisasi maka diperoleh :

$\boldsymbol{R}$ $[0,56570,62470,74540,72760,6396]$ $0,42430,46850,59630,48510,6396$ $[0,7071,62470,29810,48510,4264]$

3. Matriks Keputusan yang Ternomalisasi Terbobot

$y_{i j}=w_{i r_{i j}}$

$=\quad \mathrm{j}=1,2, \ldots, \mathrm{n}$

dengan $\quad \mathrm{i}=1,2, \ldots, \mathrm{m} \quad \mathrm{dan}$

Diketahui :

$\mathrm{W}=(5,3,4,4,2)$ $\boldsymbol{R}=\left[\begin{array}{lllll}0,5657 & 0,6247 & 0,7454 & 0,7276 & 0,6396 \\ 0,4243 & 0,4685 & 0,5963 & 0,4851 & 0,6396 \\ 0,7071, .6247 & 0,2981 & 0,4851 & 0,4264\end{array}\right]$

A. A1

$\mathrm{W} 1(\mathrm{r} 1.1)=(5)(0,5657)=2,8285$

$\mathrm{W} 2(\mathrm{r} 1.2)=(3)(0,6257)=1,8741$

$\mathrm{W} 3(\mathrm{r} 1.3)=(4)(0,7454)=2,9816$

$\mathrm{W} 4(\mathrm{r} 1.4)=(4)(0,7276)=2,9104$

W5 $($ r 1.5) $=(2)(0,6396)=1,2792$

B. A2

$\mathrm{W} 1(\mathrm{r} 2.1)=(5)(0,4243)=2,1215$

$\mathrm{W} 2(\mathrm{r} 2.2)=(3)(0,4685)=1,4055$

W3 $($ r 2.3) $=(4)(0,5963)=2,3852$

W4 (r 2.4) $=(4)(0,4851)=1,9404$

W5 $($ r 2.5) $=(2)(0,6396)=1,2792$

C. A3

$\mathrm{W} 1(\mathrm{r} 3.1)=(5)(0,7071)=3,5355$

$\mathrm{W} 2(\mathrm{r} 3.2)=(3)(0,6247)=1,8741$

W3 $($ r 3.3$)=(4)(0,2981)=1,1924$

W4 (r 3.4) $=(4)(0,4851)=1,9404$

W5 $($ r 3.5$)=(2)(0,4264)=0,8528$

Maka di peroleh Matriks Y sebagai berikut:

$\boldsymbol{Y}=\left[\begin{array}{lllll}2,8285 & 1,8741 & 2,9816 & 2,9104 & 1,2792 \\ 2,1215 & 1,4055 & 2,3852 & 1,9404 & 1,2792 \\ 3,5355 & 1,8741 & 1,1924 & 1,9404 & 0,8528\end{array}\right]$,

4. Matriks Solusi ideal positif (+) dan negative (-)

$A^{+}=\left(y_{1}^{+}, y_{2}^{+}, \ldots, y_{n}^{+}\right) \quad$ dimana :

$A^{-}=\left(y_{1}^{-}, y_{2}^{-}, \ldots y_{n}^{-}\right)$ 
$y_{j}^{+}$adalah : - $\max y_{i j}$, jika $\mathrm{j}$ adalah atribut keuntungan

$-\min y_{i j}$, jika $\mathrm{j}$ adalah atribut

biaya

$y_{j}^{\bar{j}}$ adalah : $-\max y_{i j}$, jika $\mathrm{j}$ adalah atribut keuntungan

-min $y_{i j}$, jika j adalah atribut

biaya

Solusi ideal positif :

$y_{1}^{+}=\max \{2,8285 ; 2,1215 ; 3,5355\}=3,5355$

$y_{2}^{+}=\max \{1,8741 ; 1,4055 ; 1,8741\}=1,8741$

$y_{a}^{+}=\max \{2,9816 ; 2,3852 ; 1,1924\}=2,9816$

$y_{4}^{+}=\max \{2,9104 ; 1,9404 ; 1,9404\}=2,9104$

$y_{5}^{+}=\max \{1,2792 ; 1,2792 ; 0,8528\}=1,2792$

$\mathrm{A}^{+}$

$=$

$\{3,5355 ; 1,8741 ; 2,9816 ; 2,9104 ; 1,2792\}$

Solusi ideal negatif :

$y_{1}=\min \{2,8285 ; 2,1215 ; 3,5355\}=2,1215$

$y_{\overline{2}}=\min \{1,8741 ; 1,4055 ; 1,8741\}=1,4055$

$y^{-}=\min \{2,9816 ; 2,3852 ; 1,1924\}=1,1924$

$y_{\overline{4}}=\min \{2,9104 ; 1,9404 ; 1,9404\}=1,9404$

$y_{\overline{5}}=\min \{1,2792 ; 1,2792 ; 0,8528\}=0,8528$

$A^{-}$

$\left\{2,1215 ; 1,4055_{;} ; 1_{s} 1924 ; 1_{s} 9404_{s} 0,8528\right\}$

Jarak adalah alternative $A_{i}$ dengan solusi ideal positif dirumuskan sebagai :

$D_{i}^{+}=\sqrt{\sum_{j=i}^{n}\left(Y_{i}^{+}-y_{i j}\right)} \quad 2 ; i=1,2, \ldots, m$

Jarak adalah alternatif $A_{i}$ dengan solusi ideal negatif dirumuskan sebagai

$D_{i}^{-}={\sqrt{\sum_{j=i}^{n}\left(y_{i j}-y_{i}^{-}\right)}}^{2} ; i=1,2, \ldots, \mathrm{m}$

\section{SIMPULAN}

Dari alur pengerjaan sebelumnya dapat ditarik kesimpulan yaitu dapat membantu Ketua STMIK STIKOM Bali dalam mengambil keputusan untuk memberikan penghargaan kepada Dosen Teladan dengan beberapa kriteria yang sudah ditentukan dan sudah dibantu dengan penerapan metode TOPSIS. Untuk alur proses pada penelitian ini menggunakan diagram konteks dan diagram level 0 yang dimana sudah menjelaskan bagaimana alur proses yang akan dijalankan nantinya.

\section{Daftar Pustaka}

[1] Andriyendi, Rahmadi. 2011.Aplikasi AHP Sebagai Model SPK Pemilihan Dosesn. Jurusan Manajemen Informatika. Seminar Nasional Aplikasi Teknologi Informasi (2011)

[2] Kendall, K.E dan Kendall, J.E. 2003. Analisis dan Perancangan Sistem. PT Prenhallindo dan Pearson Education Asia Pte, Ltd: Jakarta

[3] Kusumadewi, Sri., Hartati, S., Harjoko, A., dan Wardoyo, R. Fuzzy Multi-Attribute Decision Making (FUZZY MADM). Yogyakarta: Penerbit Graha Ilmu, 2006

[4] Levin, Richard 1, et al, 2002, Pengambilan Keputusan Secara Kuantitatif, edisi ke 7, Raja Grafindo Persada

[5] Widiyanto Hadi, Dany Fajar Kristianto S.W. 2012. Sistem Penunjang Keputusan Pemilihan Mahasiswa Berprestasi Menggunakan Metode Profile Matching. AMK Cipta Darma Surakarta. Confrence On Information Technology, Information System and Electrical Engineering 